\title{
Mechanisms for kinetic hydrate inhibitors
}

\author{
BJØRN KVAMME, REMI ÅSNES \\ Department of Physics, \\ University of Bergen \\ Allègt. 55, 5007 Bergen, \\ NORWAY \\ http://web.ift.uib.no/php/php/bkvamme.html
}

\begin{abstract}
The importance of kinetic hydrate inhibitors is increasing due to its low cost compared to thermodynamic inhibitors and the corresponding benefits for exploitation of small marginal fields. This stimulates further investigations of the primary mechanisms for the induction times before onset of massive hydrate growth. The hypothesis in this work is that combinations of transport rate limitations and reduced contact area between water and hydrate former may account for very much of the delay. We demonstrate this by simplified calculations, which compares well with available experimental results.
\end{abstract}

Key-Words: - kinetics; methane; water; hydrate; inhibitor

\section{Introduction}

Two types of inhibitors that are presently not used much in commercial industry are the kinetic inhibitor and anti agglomerates. Most of these inhibitors are built up from polymer blends that are easily produced and as such represent a low cost compared to the thermodynamic inhibitors. Practical applications has shown that kinetic inhibitors can prevent hydrate plugging of flow for many hours even at sub-cooling of $10-12^{\circ} \mathrm{C}$ below the hydrate equilibrium temperature at the actual pressure. These inhibitors shows efficient hydrate prevention and have a much lower cost compared to the traditional inhibitors. Kinetic inhibitors show efficient hydrate prevention at low concentration, approximately 0,5 weight percent of the free water phase is a normal configuration. The cost of producing kinetic inhibitors is much lower compared to a thermodynamic inhibitor and the kinetic inhibitors are less toxic and environmentally hazardous. On site experiments have shown that the kinetic inhibitors can be injected with the same equipment that is being used for traditional inhibitors today with minor changes due to the low injection rate. Tests have shown that kinetic inhibitors do not create foaming and emulsion problems later in the process, [1]. In the same article it is stated that the eco-toxicity tests performed on produced water during polymer injection; showed that the water quality fulfilled the current guidelines for water discharge in the Gulf of Mexico. Water tests also showed that very little of the injected polymers would follow the free water phase, due to its hydrophobic nature. The measured polymer values in the water phase were as low as $2 \%$ of the injection rate. The polymer present in the hydrocarbon phase did not affect the performance of the further oil and gas processing.

Many experiments have shown that the kinetic inhibitors prevent hydrates, but the commercial use is still small. The experimental set up is expensive and time consuming; one of the goals in this thesis is therefore to find reasonably good calculation methods to sort the inhibitors performance. If it was possible to calculate the inhibitor performance the extent of experimental testing would be reduced, and the testing could be reduced to include the inhibitors that performed well in theoretic calculations.

Hydrate induction time is the time lag before onset of massive hydrate growth in heterogeneous hydrate formation. In a stirred batch system it is typically seen as an initial limited consumption of hydrate formers $[1,2]$ followed by a variable time lag which depends on the sub-cooling, density of hydrate former and contact area. The contact area is typically manipulated through the stirring rate. Interpretation of unstirred experimental systems [3] shows that hydrate particles on methane/water interface rearrange so that some particles disappear in favour of larger and more stable particles. A recent study using Magnetic Resonance Imaging (MRI) also confirmed induction time in the order of 100 hours for the system methane/water at 83 bar and $3 \mathrm{C}$ [4]. In this work we use Phase Field Theory to study how the free energy in the systems directs heterogeneous hydrate growth patterns and the consequences this might have on the possible mechanisms for the onset of macroscopic hydrate growth.

\section{Numerical simulations}

In order to create hydrate in a system some thermodynamic and kinetic mechanisms must be present. Considering the thermodynamic processes involved in hydrate formation the phase transaction is one of the major contributors in the hydration process. To create a hydrate phase both water and gas must be 
forced into the new hydrate phase together. This leads to the nucleation phase where the water molecules start clustering around the gas molecules trying to reach thermodynamic stability. For the nucleuses to become thermodynamically stable the free energy gain of the phase transaction must overcome the penalty of work performed on the surroundings. When this happens the nucleuses have reached what is called the critical size and in this state further growth is more energetic preferable than the dissolving of the nucleuses. In the growth stage the driving force will be the same as in the nucleation step, the free energy change involved in the phase transactions will make continued growth preferable. After some time the interface will be covered with hydrate and the gas transport will not reach the liquid interface until the hydrate layer breaks and/or rearranges. When the hydrate structure allows for gas transport the gas concentration will have accumulated at the hydrate interface, this results in rapid uncontrolled growth when the gas again reaches the liquid interface.

The thermodynamic driving forces acting on a hydrate system is intimately coupled to the transport processes. Heat transport is typically very rapid for these systems and mass transport is essentially the dominating limiting transport process [3 - 9]. In order to produce hydrate there must be a transport of gas from bulk to the liquid interface. The corresponding flux will in the following be denoted as $J_{1}$. If the system consists only of a liquid and a vapor phase the gas flow would typically not be any limitation for the hydrate nucleation or growth. For the systems considered in this work, however, there is also a polymer phase present and this will limit the gas transport to the liquid interface. The mass transport of gas through the polymer layer is limited by the gas diffusivity though the polymer and the concentration gradient from bulk to the liquid interface. The flux through the polymer will be denoted as $\mathrm{J}_{2}$ and the flux of hydrate former further into the aqueous phase will be denoted as $\mathrm{J}_{3}$. When a hydrate film is formed there will be an additional flux of methane through the hydrate film before methane can reach aqueous solution. This flux is denoted as $J_{4}$ and expected to be at least three orders of magnitude lower than $\mathrm{J}_{3}[10]$.

In the experimental setup described by Kiellandet.al.[2] the samples were stirred during the experiments. Due to the stirring in the experiments the gas transport would be subjected to some turbulence forces which might have influenced the nucleation and growth rate. In the calculations performed in this work these effects are not accounted for.

The main hypothesis in this work is that the kinetic inhibitors main contribution related to hydrate inhibition is a result of the limited gas transport through the polymer layer and the reduced contact area between aqueous solution and hydrate former due to the polymer packing.

An estimate for the self-diffusion flux $J_{1}$ may be achieved from the revised Enskog equation [11, 12] through the assumption that the gas flux is only limited by its own random motions:

$$
\begin{aligned}
& D^{\text {Enskog }}=\frac{3}{8 n} \frac{1}{a^{2} g_{2}^{H S}\left(a^{+}\right)}\left(\frac{k_{B} T}{\pi m}\right)^{1 / 2}, \\
& g_{2}^{H S}\left(a^{+}\right)=\left[q_{1}+q_{2} e\left(\frac{-\varepsilon}{k T}\right)\right] \exp \left[q_{3}\left(\rho \sigma^{3}\right)\right]
\end{aligned}
$$

where $n$ is the particle density, $a$ is the particle diameter, $m$ is the particle mass, $k_{B}$ is Boltzmann's constant, $g^{H S}$ is the hard core contact value of the paircorrelation function. The energy of interaction parameters in the modified Enskog theory [12] for methane are $\varepsilon_{e} / \mathrm{k}_{\mathrm{B}}=$ $148,2 \mathrm{~K}$ and a diameter $\sigma$ equal to 3,81 $\AA$. $\rho$ is the molecular density. Factors $\mathrm{q}_{1}, \mathrm{q}_{2}$ and $\mathrm{q}_{3}$ are given in [12].

The flux $\mathrm{J}_{2}$ is estimated through a modified [13] version of Knudsen diffusion [14] using temperature dependent diffusivities $D_{k}$ and effects of free internal diffusivity of methane in the bulk of the channels, $D_{\mathrm{i}}$ :

$D_{\text {eff }}=\frac{\varepsilon}{\tau} \frac{1}{\frac{1}{D_{i}}+\frac{1}{D_{k}}}$

$D_{i}=\frac{0,001858 T^{\frac{3}{2}}\left[\left(\frac{2}{M}\right)^{\frac{1}{2}}\right]}{P \sigma_{i}^{2} \Omega_{D}}$

$$
D_{k}=\frac{d_{\text {pore }}}{3} \sqrt{\frac{8 R T}{\pi M}}, D_{k}=D_{0} \exp \left(\frac{-E_{D}}{R T}\right)
$$

where $M$ is the molecular weight of the diffusing particle, $d_{\text {pore }}$ is pore diameter, $\mathrm{E}_{\mathrm{D}}$ is the activation energy, $\sigma_{i}^{2}$ is the effective collision diameter and $\Omega_{D}$ is the collision integral. For a high density polymer like PVCap the diffusivity is $5.7 \cdot 10^{-12} \mathrm{~m}^{2} / \mathrm{s}$ [15] and for a lower density polymer like VC713 the diffusivity is $1.9 \cdot 10^{-11} \mathrm{~m}^{2} / \mathrm{s}$ [15]. The flux $\mathrm{J}_{3}$ is calculated through Fix law using a diffusivity of methane in aqueous solution of $2.3 \cdot 10^{-9} \mathrm{~m}^{2} / \mathrm{s}$, and solubility of methane in water from Lekvam \& Bishnoi [16]. The total pathway of transport though liquid water is the sum of two distances. The inhibited transport though polymer soaked into the 
aqueous phase due to gravity and the subsequent transport in "free" aqueous phase. The first one is calculated by a simple mechanical balance.

The nucleation of hydrate can not occur before methane has migrated through the polymer and is thus governed by the limiting steps of $\mathrm{J}_{1}, \mathrm{~J}_{2}$ and $\mathrm{J}_{3}$. This gives the first delay in induction time (here defined as onset of massive hydrate growth). A second delay comes after the initial microscopic hydrate film has been formed and the transport of methane is limited by transport through massive hydrate with an assumed diffusivity coefficient of $1.0 \cdot 10^{-12} \mathrm{~m}^{2} / \mathrm{s}$ and corresponding limiting flux $\mathrm{J}_{4}$. In this work we use simple classical nucleation theory [17] together with thermodynamic properties from Svandal et.al. [8,9] and Kvamme \& Tanaka [18]. Table 1 list experimental conditions and corresponding absolute values of free energy changes for the hydrate phase transition (negative fre energy changes). Corresponding predicted delay times for onset of massive hydrate growth is plotted in fig. 1 together with experimental data

\begin{tabular}{|l|l|l|l|l|}
\hline & $\begin{array}{l}\text { PVCap } \\
\text { Mw=7500 }\end{array}$ & $\begin{array}{l}\text { PVCap } \\
\mathbf{M w}=1300\end{array}$ & $\begin{array}{l}\text { VC713 } \\
\mathbf{M w}=\mathbf{4 5 0 0}\end{array}$ & $\begin{array}{l}\text { VC713 } \\
\mathbf{M w}=\mathbf{4 5 0 0}\end{array}$ \\
\hline Temp. $(\mathrm{K})$ & 280,75 & 276,85 & 278,95 & 277,05 \\
\hline$\Delta \mathrm{G}(\mathrm{J} / \mathrm{mol})$ & 2530,44 & 2504,82 & 2518,33 & 2506,01 \\
\hline
\end{tabular}

Table 1 Temperature and free energy differences $[8,9,18]$ in the experiments [2].

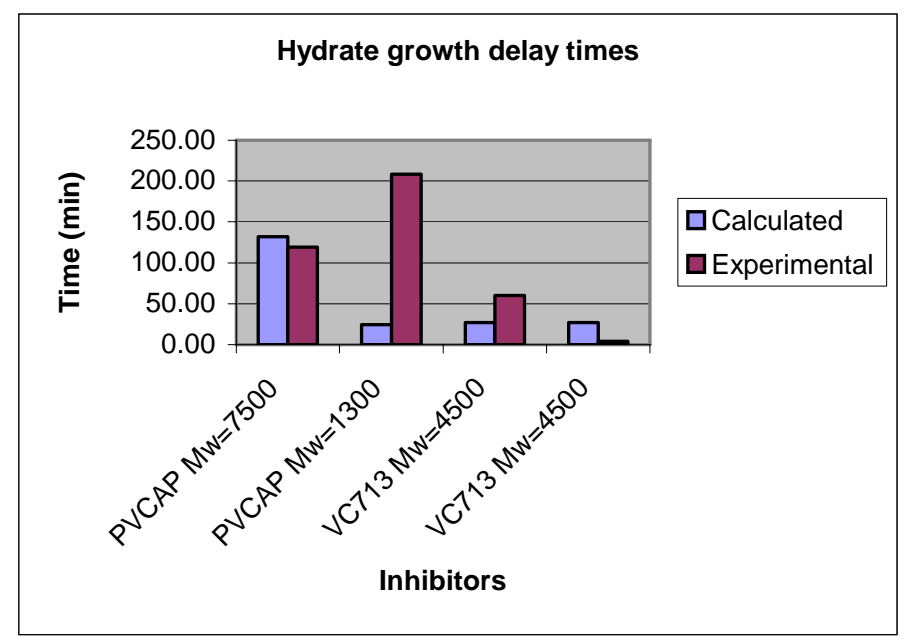

Figure 1. Estimated and experimentally observed [2] delay times for onset of massive growth for two kinetic hydrate inhibitors at different concentrations.

\section{Discussion and conclusions}

Major portions of the differences between PVCap and VC713 seem to be captured by the simplified considerations discussed in this work. The experimental result for PVCap with average MW equal to 1300 seem to be an outliner and for some reason this specific experiment is also omitted in later communication from the same experimental group. There are many additional effects that can be taken into account. The effect of stirring and the effect of water structuring and sterical hindrance due to the polar segments of inhibitors are two effects that could be looked into. The latter of these may benefit from the experience gained in molecular simulations of fluid interfaces [19-23] and may also provide means of estimating more realistic diffusivities across the relevant interfaces. Replacement of classical nucleation theory with DIT theory [24] is another possible step.

\section{References:}

[1] Frostman, L. M., Przybylinski, J. L., "Successful Applications of Anti-agglomerant Hydrate Inhibitors.", SPE International Symposium on Oilfield Chemistry, 13-16 February, Houston, Texas.

[2] Kelland, M. A., Svartaas, T. M., Øvsthus, J., Namba, T., "A new Class of Kinetic Hydrate Inhibitor.", Ann NY Acad Sci., vol. 912, (2000), pages: 281-293.

[3] Kvamme, B, Graue, A., Aspenes, E., Kuznetsova, T., Gránásy, L., Tóth, G., Pusztai, T.,Tegze G. Towards understanding the kinetics of hydrate formation: Phase field theory of hydrate nucleation and magnetic resonance imaging, Physical Chemistry Chemical Physics, 2004, 6, 2327 - 2334

[4] Granasy, L., Pusztai, T., Tegze, G., Kuznetsova, T., Kvamme, B. Phase field theory of hydrate nucleation: Formation of $\mathrm{CO} 2$ hydrate in aqueous solution, in "Recent Advances in the Study of Gas Hydrates", Kluwer Academic/Plenum Publishers, 2004

[5] Svandal A., Kvamme B., Grànàsy L., Pusztai T. The phase field theory applied to $\mathrm{CO}_{2}$ and $\mathrm{CH}_{4}$ hydrate. $J$. Cryst. Growth., 2006, 287, p. $486-490$

[6] Gránásy, L, T Pusztai, T. and J Warren., J. Modelling polycrystalline solidification using phase field theory. Jorurnal of Physics: Condensed Matter, 2004, 16(41), p.1205- 1235

[7] Tegze, G., Pusztai, T., Tóth, G., Gránásy, L., Svandal, A., Buanes, T., Kuznetsova, T., Kvamme, B., Multi-scale approach to $\mathrm{CO}_{2}$-hydrate formation in aqueous solution: Phase field theory and molecular dynamics. Nucleation and growth, J. Chem. Phys, 2006, 124,234710

[8] Svandal, A., Kuznetsova, T., Kvamme, B. Thermodynamic properties and phase transtions in the $\mathrm{H}_{2} \mathrm{O} / \mathrm{CO}_{2} / \mathrm{CH}_{4}$ system, Physical Chemistry Chemical Physics, 2006, 8, 1707 - 1713

[9] Svandal, A., Kuznetsova, T., Kvamme, B., " Thermodynamic properties interfacial structures and phase transtions in the $\mathrm{H}_{2} \mathrm{O} / \mathrm{CO}_{2} / \mathrm{CH}_{4}$ system", Fluid Phase Equilibria, 2006, 246, 177-184 
[10] Radhakrishnan R., Demurov A., Herzog H.,Trout B.L.: A consistent and verifiable macroscopic model for the dissolution of liquid $\mathrm{CO} 2$ in water under hydrate forming conditions, Energy Conversion and Management, 44, 771-780, 2003.

[11] Polewczak, J., Stell, G., "Transport coefficients in some stochastic models of the revised Enskog equation", Journal of Statistical Physics, vol. 109, (2002), pages: 569-590.

[12] Matteoli, E., Mansoori, G. A., "A simple expression for radial distribution functions of pure fluids and mixtures", Journal of Chemical Physics, vol. 103, No. 11, (1995), pages: 4672-4677.

[13] Subrata, R., Reni, R., Chuang, H. F., Cruden, B. A., Meyyappan, M., "Modeling gas flow through microchannels and nanopores", Journal of Applied Physics, vol. 93, No. 8, 2003, pages: 4870-4879.

[14] McCabe, W. L., Smith, J. C., Harriot, P., "Unit Operations of Chemical Engineering", 6. edition 2001.

[15] Flaconnéche, B., Martin, J., Klopffer, M. H., "Permeability and Solubility of Gases in Polyethylene, Polyamide 11 and Poly(vinylidene fluoride)", IFP, vol. 56, No. 3, (2001), pages: 261-278.

[16] Lekvam, K., Bishnoi, P. R., "Dissolution of methane in water at low temperatures and intermediate pressures", Fluid Phase Equilibria, vol. 131, (1997), pages: 297-309.

[17] Kashiev, D. Nucleation - Basic theory with applications. Butterworth-Heinemann, Jordan Hill Oxford, GB, 2000.

[18] Kvamme, B and Tanaka, H. Thermodynamic stability of hydrates for ethane, ethylene and carbon dioxide. J. Chem. Phys., 99:7114-7119, 1995.

[19] Kvamme, B., Kuznetsova, T. Aasoldsen, K., "Molecular dynamics simulations for selection of kinetic hydrate inhibitors", Journal of Molecular Graphics and Modelling, vol. 23, (2005), 524-536

[20] Kuznetsova, T., Kvamme, B., "Thermodynamic properties and surface tension of model water-carbon dioxide systems", Physical Chemistry Chemical Physics, (2002), (4), 937-941.

[21] Kuznetsova, T., Kvamme, B., "Viabilty of Atomistic Potentials for Thermodynamic Properties of Carbon Dioxide at Low Temperatures. Journal of Computational Chemistry", vol. 22, (2001), 1772.

[22] Kuznetsova, T., Kvamme, B., "Atomistic Computer Simulations for Thermodynamic Properties of Carbon Dioxide at Low Temperatures", Energy Convers. Mgmt., vol. 43, (2002), pages: 2601-2623.

[23] Kvamme, B., Kuznetsova, T., Hebach, A., Oberhof, A., Lunde, E., "Measurements and modeling of interfacial tension for water+carbon dioxide systems at elevated pressures", Computational Material Sciences, (2006), in press.
[24] Kvamme, Bjørn. Initiation and growth of hydrate from nucleation theory. International Journal of Offshore and Polar Engineering 2002; 12(4):256-262 